\title{
Intensity of Artificial Lighting in Living Room and Study Area of Urban Residential Homes in Dharwad City
}

\author{
Shilpa Nandi and Susheela Sawkar \\ Department of Family Resource Management, Rural Home Science College \\ University of Agricultural Sciences, Dharwad, Karnataka, India
}

KEYWORDS Lux. Intensity of light. Artificial Light. Luxmeter

\begin{abstract}
Light enables us to view, perceive and enjoy the various forms of visual communication. Good and efficient lighting is essential for every home and improvements have been made during recent years. Now-a days human drive towards utilization and dependence on artificial light is the need of the hour. Hence the present study was undertaken with an objective to determine the existing artificial lighting and compare with the recommended standards. Research on adequacy of the artificial lighting was undertaken in ninty residential homes of different income group. Structured schedule cum interview method was used to collect data and intensity was measured by the Digital Luxmeter. Mean intensity of arficial lighting was highly inadequate compared to the recommended standards. The reason may be the lack of awareness, understanding and appreciation of the importance of well planned lighting in daily living. Light whether natural or artificial must be adequate if eyesight is to be protected. The source and intensity of light must be as per requirement. When there is adequate source of light one can work with ease, there is less tension, heart rate is close to normal due to less strain and general sensitivity of the visual sence is greater.
\end{abstract}

\section{INTRODUCTION}

Light is indicative of purity . Light enables us to view, perceive and enjoy the various forms of visual communication. Good and efficient lighting is essential for every home. Interiors are properly brought to light. i.e., with well planned artificial lighting in interiors. Morris (1959) defined good lighting as "the right kind and right amount of light at the right place". Artificial lighting as needed to provide task illuminance and adequate visual environment to carry on the tasks when natural light is inadequate or not available. Good artificial illumination enables well lit surroundings, visual comfort, prevent accidents, protects health by minimizing eye strain and also contribute to the beauty in homes. Inadequate light may lead to problems like lack of interest, failure to concentrate, sleepiness and apparent laziness. Further, eyestrain, headache, indigestion and irritability are the other problems due to inadequate light. In residential homes, the living room being used for different kinds of activities like, relaxation, family entertainment, get together etc., which require variety of lighting techniques. Study room / area is also an important area where a lot of close visual tasks and skilled work are performed which require suitable type of lighting of adequate quantity. So dependence on artificial light is need of the hour. Hence the present study was undertaken to investigate the adequacy of artificial lighting in living room and study area of urban residential homes of Dharwad city.

\section{METHODOLOGY}

The study was conducted in Dharwad city of Karnataka state during the year 1998-99 with reference to different socio-economic group for which the classification given by HUDCO (1998) as low income group (LIG), Middle income group (MIG) and High income group (HIG). Totally 90 households were selected, 30 each from three income groups. "Digital Luxmeter" was the equipment used to measure the quantity of artificial light in living room and study area.

Readings for artificial light in selected area were taken from 7 to $9 \mathrm{pm}$. The living room was divided into 20 equal parts and study area into 4 equal parts to measure the intensity of artificial light. The readings were taken by keeping the digital luxmeter horizontally at the centre of each part and the mean intensity of the artificial light available was calculated.

\section{RESULTS AND DISCUSSION}

The intensity of artificial light existing in living room was 69.28 Lux whereas the recommended standards were 300 Lux as per Vargheese etal. 1985. In study area, the artificial light intensity was 78.04 Lux for which the recommended standards was 150 Lux as per 
Indian Standard Code of Practice for Interior Illumination (Anonymous, 1992) Table 1.

Table 1: Comparison of existing intensity of artificial light in living room and study area to the recommended standards

\begin{tabular}{|c|c|c|c|c|}
\hline \multirow[t]{2}{*}{ Particulars } & \multicolumn{4}{|c|}{ Intensity of light } \\
\hline & $\begin{array}{l}\text { Existing } \\
(\text { Lux })\end{array}$ & $\begin{array}{c}\text { Stan- } \\
\text { dard } \\
\text { devia- } \\
\text { tion }\end{array}$ & $\begin{array}{c}\text { Recom- } \\
\text { mended } \\
\text { stan- } \\
\text { dard } \\
(\text { Lux })\end{array}$ & $\begin{array}{c}\text { Percentage } \\
\text { of inadequacy } \\
\text { of light }\end{array}$ \\
\hline Living room & 69.28 & 21.13 & 300 & 76.90 \\
\hline Study area & 72.04 & 22.42 & 150 & 51.97 \\
\hline
\end{tabular}

Percentage of inadequacy of artificial light was higher for the living rooms $(76.09 \%)$ when compared to that of the study area $(51.97 \%)$. So the assessment indicates that the artificial light intensity was inadequate in living room and study area. Possible reason might be the improper placement of bulbs and tubes and mounting height of the light fixtures, use of lower wattages of bulbs/ tubes, improper cleaning schedule of bulbs/tubes. Major contributing reason was due to the lack of awareness regarding the light intensity required to perform the different tasks. The results of the study are in line with the study conducted by Chandpilla (1964) and Zend et al (1996).

Intensity of artificial light in study area was also inadequate in the study when compared to the recommended standards and the results are inaccordance with the study of Mariamma (1971), Thygarajan et al.(1978) Lina (1989) and Zend et al (1996).

The mean intensity of artificial light in living room of the high income group was higher (72.56 Lux) when compared to middle income (68.22 lux) and low income group (68.47 Lux) (Table 2). Further, the results revealed that in study area of HIG household, the mean artificial light intensity was more (74.13 Lux) when compared to MIG (68.88 Lux) and LIG (68.09 lux). However the major reason for inadequate lighting in all the three income groups can be pin pointed to the fact of unawareness of the factors that influences lighting conditions and did not realize the need for specific illuminations required to perform the different tasks. The results of the present study are in accordance with studies by Thyagarajan (1978), Lina (1989) and Zend et al. (1996).

\section{CONCLUSION}

To conclude that in both living room and study area, the mean intensity of artificial light was much lower than the recommended standards. Hence the need of the hour is to create awareness about the serious inadequacy of living in households and ill effects, so that improvement for adequate lighting may be planned. The recommended standards for lighting also needs to be popularized.

\section{REFERENCES}

Anonymous: Indian Standard Code of Practice for Interior Illumination. IS 3646 (Part-I). Bureau of Indian Standards, Manak Bhavan, New Delhi, pp.1221. (1992).

Chandpilla: An Evaluation of the Existing Lighting System of a Representative Sample of Drawing in Ernaculum. M H Sc Thesis, filed in the College library of St.Teresa's College Ernaculum. Kerala, cited in Research in India related to Home Management Compilation of Research findings, p.157 (1964).

Lina, T.: A Study on Lighting Practices and Plans for Study Area in Residences, Bombay. M H Sc, Dissertation SNDT Women's University, Bombay (1989).

Morris, C.K.: Lighting your Home. Extension Service Institute of Agricultural Sciences, Extension Bulletin, p.533. (1959).

Thyagarajan, Nirmala., Dhatri., Prema and Sankari: Physological responses of home makers to lighting Indian Journal of Home Science, 12(4): 125-128 (1978).

Zend,J.P., Khairajani, V.H and Murali, D.,: Adequacy of artificial light in different areas of the house. Journal of Maharastra Agricultural Universities, 21(1): 97 98 (1996).

Varghese, M.A., Ogale, N.M and Srinivasan, K.: Home Management. For Std XI, Wiley Estern Limited, Bombay, pp. 120-128 (1985).

Table 2: Intensity of artificial light in living room and study area of different income groups

\begin{tabular}{|c|c|c|c|c|c|c|}
\hline \multirow[t]{2}{*}{ Particulars } & \multicolumn{2}{|l|}{$H I G(N=30)$} & \multicolumn{2}{|l|}{$M I G(N=30)$} & \multicolumn{2}{|l|}{$L I G(N=30)$} \\
\hline & Existing mean (Lux) & $S D$ & Existing mean (Lux) & $S D$ & Existing mean (Lux) & $S D$ \\
\hline Living room & 72.56 & 30.19 & 68.22 & 10.31 & 68.47 & 10.54 \\
\hline Study area & 74.13 & 31.38 & 68.88 & 11.44 & 68.09 & 10.67 \\
\hline
\end{tabular}

Note: HIG : High Income Group, MIG : Middle Income Group, LIG : Low Income Group 